\title{
Hydrogen Gas Permeation Through Amorphous and Partially Crystallized $\mathrm{Fe}_{40} \mathrm{Ni}_{38} \mathrm{Mo}_{4} \mathrm{~B}_{18}$
}

\author{
Rafaella Martins Ribeiro, Luis Fernando Lemus, Dilson Silva dos Santos*
}

\author{
Programa de Engenharia Metalúrgica e de Materiais - PEMM, \\ Coordenação de Programas de Pós-graduação em Engenharia, Instituto Alberto Luiz Coimbra de \\ Pós-graduação e Pesquisa de Engenharia - COPPE, Universidade Federal do Rio de Janeiro - UFRJ, \\ CP 68505, CEP 21941-972, Rio de Janeiro, RJ, Brazil
}

Received: December 7, 2011; Revised: June 26, 2012

\begin{abstract}
Samples of amorphous and partially crystallized $\mathrm{Fe}_{40} \mathrm{Ni}_{38} \mathrm{Mo}_{4} \mathrm{~B}_{18}$ alloy were submitted to hydrogen gas permeation from 523 to $643 \mathrm{~K}$. The hydrogen permeation curves exhibited a single sigmoidal shape, typical of tests where no hydride formation occurs. It was observed that the hydrogen diffusivity increases for the amorphous samples and partially crystallized alloy with the temperature increase. The hydrogen diffusion coefficient as a function of temperature was found to be $\mathrm{D}=5.1 \pm 0.5 \times 10^{-12} \mathrm{exp}$ $(-11.0 \pm 3.5 / \mathrm{RT})\left(\mathrm{m}^{2} \cdot \mathrm{s}^{-1}\right)$ for amorphous condition and $\mathrm{D}=3.6 \pm 0.5 \times 10^{-11} \exp (-19.8 \pm 3.3 / \mathrm{RT})\left(\mathrm{m}^{2} \cdot \mathrm{s}^{-1}\right)$ for the partially crystallized condition. This suggests that the annihilation of defects in the amorphous structure and the crystalline phase precipitate contributes to the increase of the hydrogen diffusion.
\end{abstract}

Keywords: hydrogen diffusion, amorphous metallic alloy, crystallized alloy

\section{Introduction}

Amorphous metallic alloy ribbons were exhaustively studied because of its capability to storing hydrogen and membrane application ${ }^{1-3}$. Regardless of the composition, amorphous alloys exhibit large amount of sites for hydrogen absorption, but many of this sites have high occupancy energy so the hydrogen diffusivity in these materials is always lower than the corresponding crystalline alloys. Another important remark concerning hydrogen in amorphous alloys is the ability to form hydride. Rodmacq et al. ${ }^{4}$, based on neutron diffraction experiments, reported the hydride formation in the CuTi alloy. Fagundes et al. ${ }^{5}$ studied $\mathrm{Fe}_{40} \mathrm{Ni}_{38} \mathrm{Mo}_{4} \mathrm{~B}_{18}$ amorphous alloy, by electrochemical permeation tests, and observed the hydride formation. The hydride formation was attributed to the double sigmoidal shape exhibited in the hydrogen permeation curves despite the fact that the hydride could not be confirmed by X-ray diffraction (XRD) after hydrogenation because the amorphous structure did not change. In contrast to these results, the literature ${ }^{6,7}$ reported no occurrence of hydride in amorphous alloys which has strong ability to form hydride when crystalline.

The present work aims to studying the amorphous and partially crystallized $\mathrm{Fe}_{40} \mathrm{Ni}_{38} \mathrm{Mo}_{4} \mathrm{~B}_{18}$ alloy by hydrogen gas permeation at high temperature.

\section{Experimental Procedure}

The alloy, made by melt-spinning with nominal composition $\mathrm{Fe}_{40} \mathrm{Ni}_{38} \mathrm{Mo}_{4} \mathrm{~B}_{18}$, was supplied by Allied Signal $\mathrm{Co}$ in the form of ribbons $25.4 \mathrm{~mm}$ wide and $25 \mu \mathrm{m}$ thick. Isothermal heat treatment was carried out at $698 \mathrm{~K}$ during 30 minutes under an inert atmosphere to promote the partial crystallization of the sample. The crystallization temperature

*e-mail: dilson@metalmat.ufrj.br was chosen from the differential scanning calorimetry tests, DSC, performed previously ${ }^{8}$.

The XRD was performed in a Shimadzu XRD-6000 apparatus using $\mathrm{Cu}-\mathrm{K} \alpha$ radiation, before and after the heat treatment to evaluate the occurrence of the sample crystallization.

Hydrogen gas permeation tests were performed from 523 to $643 \mathrm{~K}$ in a home apparatus with a double compartment cell that are separated by the sample. After vacuum and rinse with argon, $1 \mathrm{MPa}$ of a constant hydrogen pressure was applied and in the opposite side the compartment was kept under $\sim 10^{-7}$ torr of vacuum, using a turbo molecular pump. The hydrogen, that diffuses through the sample arrives in the opposite compartment is immediately released to the compartment due to the negative pressure, maintaining the hydrogen concentration always zero. The hydrogen flux is measured by using the mass flow meter Omega FMA-1600 A with a data collection interval of $100 \mathrm{~ms}$. Based on this configuration, the initial and boundary conditions are given by:

- for $\mathrm{t}=0 \mathrm{C}_{0}=0,0 \leq \mathrm{x} \leq \mathrm{L}$

- for $\mathrm{t}>0 \mathrm{C}_{0}=\mathrm{C}_{1}$ and $\mathrm{C}_{\mathrm{L}}=0$

Applying these conditions to Fick's second law, it is possible to obtain the flux evolution as a function of time, $\mathrm{J}_{\mathrm{L}}(\mathrm{t})$, as shown in Equation 1, assuming that the diffusivity of hydrogen does not vary with the concentration increase.

$J_{L}(t)=J_{\infty}\left(1+2 \sum_{1}^{n}(-1)^{n} \exp \left(\frac{-n^{2} \pi^{2} D t}{L^{2}}\right)\right)$

where $\mathrm{J}_{\infty}$ is the steady state flux, $\mathrm{D}$ is the hydrogen diffusion coefficient, $\mathrm{L}$ is the sample thickness and $\mathrm{n}=1,2,3, \ldots$. 
The dependence of the diffusion coefficient with temperature is given by:

$$
D=D_{0} \exp \left(-\frac{Q}{R T}\right)
$$

where $\mathrm{D}_{0}$ is the diffusion coefficient independent of temperature and $\mathrm{Q}$ is the driving force.

\section{Results and Discussion}

Figure 1 shows the XRD spectra of the alloy as received and after isothermal annealing, where the beginning of crystallization can be seen that occurs after the relaxation

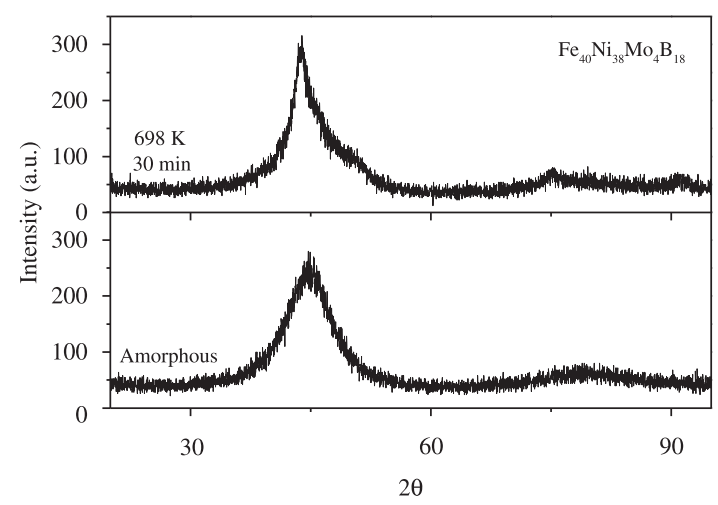

Figure 1. $\mathrm{XRD}$ of $\mathrm{Fe}_{40} \mathrm{Ni}_{38} \mathrm{Mo}_{4} \mathrm{~B}$ 要 amorphous alloy ribbon before and after heat treatment at $698 \mathrm{~K}$ during 30 minutes.

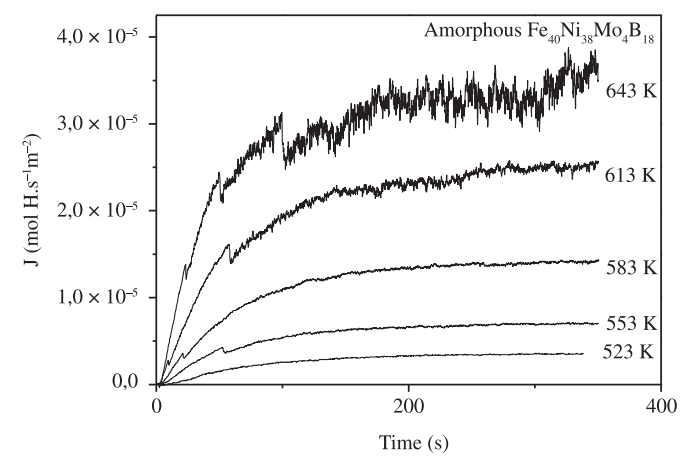

(a)

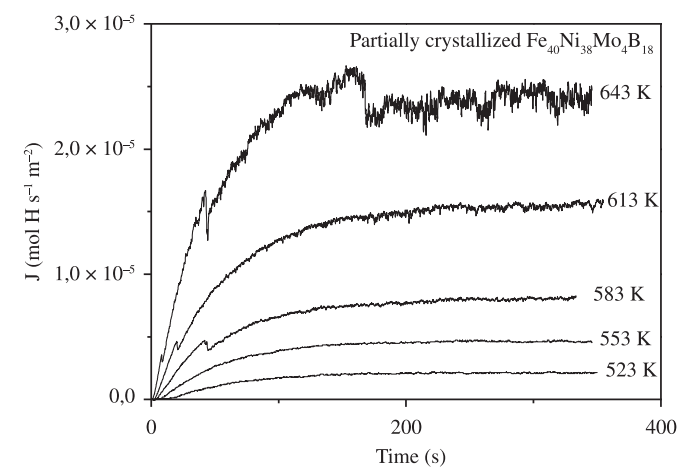

(b)

Figure 2. Permeation curves for (a) amorphous and (b) partially crystallized $\mathrm{Fe}_{40} \mathrm{Ni}_{38} \mathrm{Mo}_{4} \mathrm{~B}_{18}$ at temperatures from 523 to $643 \mathrm{~K}$. process of the sample. Du et al. ${ }^{8}$ performed in situ X-ray diffraction to study the $\mathrm{Fe}_{40} \mathrm{Ni}_{38} \mathrm{Mo}_{4} \mathrm{~B}_{18}$ crystallization at $693 \mathrm{~K}$ for different annealing times, and the crystallization product was found to be $\mathrm{Fe}-\mathrm{Ni}$ phase and (FeNiMo) ${ }_{23} \mathrm{~B}_{6}$ phase appears after 48 hours of annealing.

The hydrogen permeation curves, obtained at $1 \mathrm{MPa}$ from 523 to $643 \mathrm{~K}$ for amorphous and partially crystallized conditions, are shown in Figure 2. It can be seen that all curves exhibit a sigmoidal shape, indicating no hydride formation. Two aspects must be considered for this behavior: the increase of the temperature and the low hydrogen pressure used in the test $(1 \mathrm{MPa})$. In general, the occurrence of hydrides is strongly affected by the increase of the temperature. At high temperatures, the transition of solid solution to hydride can occurs instantaneously i.e. without providing a pressure plateau, which depends on the alloy. These factors contribute to the increase of the hydrogen amount in the alloy.

The permeability of the studied alloy is about $10^{-9}$ mol. $\mathrm{m}^{-1} \mathrm{~s}^{-1} \mathrm{~Pa}^{-0.5}$ at $643 \mathrm{~K}$. This value is in agreement with the results obtained by Kim et al. ${ }^{9}$ for the alloy $\left(\mathrm{Ni}_{0.6} \mathrm{Nb}_{0.4}\right)_{90} \mathrm{Zr}_{10}$ used in hydrogen filters, which has an alloying element with greater affinity to hydrogen than the alloy studied in this work.

Figure 3 shows the hydrogen diffusivity for the amorphous and partially crystallized conditions compared to the results previously obtained in electrochemical permeation tests 5 . The hydrogen diffusivity in the amorphous sample can be expressed as a function of temperature by the relation $\mathrm{D}=5.1 \pm 0.5 \times 10^{-12} \exp (-11.0 \pm 3.5 / \mathrm{RT})\left(\mathrm{m}^{2} . \mathrm{s}^{-1}\right)$ and $\mathrm{D}=3.6 \pm 0.5 \times 10^{-11} \exp (-19.8 \pm 3.3 / \mathrm{RT})\left(\mathrm{m}^{2} . \mathrm{s}^{-1}\right)$ for the partially crystallized sample.

It can be seen that the hydrogen diffusion in the sample after partial crystallization is slightly higher than in the amorphous structure. This occurs due to the mechanisms of annihilation of defects in conjunction with the appearance of ordered crystals embedded in an amorphous structure, which can increase diffusion rate.

Table 1 summarizes the results of $\mathrm{D}_{0}$ and $\mathrm{Q}$, obtained from Figure 3, and the comparison to previous studies ${ }^{5}$.

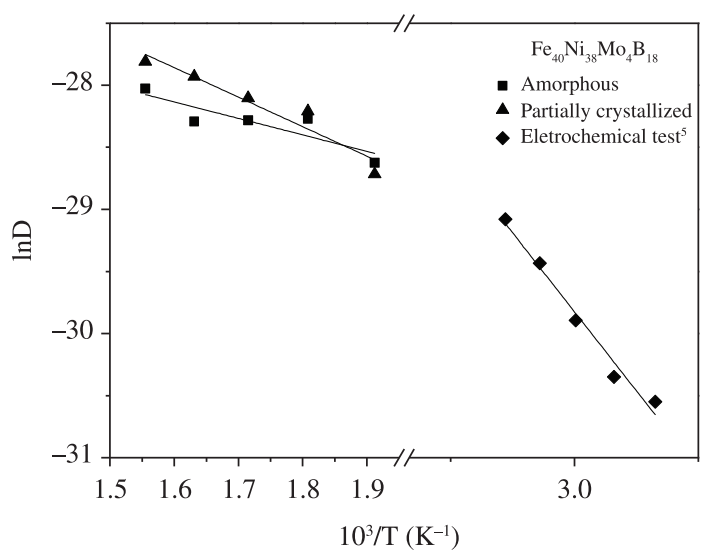

Figure 3. Hydrogen diffusivity for amorphous and partially crystallized conditions obtained by gas permeation and electrochemical tests ${ }^{5}$. 
Table 1. Diffusivity results as a function of the temperature obtained in this study and the comparison with literature data for crystalline alloys.

\begin{tabular}{lcccc}
\hline \multicolumn{5}{c}{ Hydrogen diffusivity } \\
\hline \multicolumn{1}{c}{ Materials } & $\begin{array}{c}\mathbf{D}_{\mathbf{0}} \\
\left(\mathbf{m}^{\mathbf{2}} \cdot \mathbf{s}^{-1}\right)\end{array}$ & $\begin{array}{c}\mathbf{Q} \\
\left(\mathbf{K J} . \mathbf{m o l}^{\mathbf{1}}\right)\end{array}$ & $\Delta \mathbf{T}$ & Reference \\
\hline $\mathrm{Fe}_{40} \mathrm{Ni}_{38} \mathrm{Mo}_{4} \mathrm{~B}_{18}$ & $3.8 \times 10^{-8}$ & $35.5 \pm 2.9$ & $313-353$ & 5 \\
\hline $\mathrm{Fe}_{40} \mathrm{Ni}_{38} \mathrm{Mo}_{4} \mathrm{~B}_{18}$ & $5.1 \times 10^{-12}$ & $11.0 \pm 3.5$ & $523-643$ & this study \\
$\mathrm{Amorphous}$ & & & & \\
\hline $\begin{array}{l}\mathrm{Fe}_{40} \mathrm{Ni}_{38} \mathrm{Mo}_{4} \mathrm{~B}_{18} \\
\begin{array}{l}\text { Partially } \\
\text { crystallized }\end{array}\end{array}$ & $3.6 \times 10^{-11}$ & $19.8 \pm 3.3$ & $523-643$ & this study \\
\hline
\end{tabular}

The gap between the measurements of the electrochemical permeation refers to the inability to perform this test at temperatures above $353 \mathrm{~K}$. In the same way for temperatures below $523 \mathrm{~K}$, the hydrogen permeation through the alloy is very low.

It is important to note that the product of crystallization of $\mathrm{Fe}_{40} \mathrm{Ni}_{38} \mathrm{Mo}_{4} \mathrm{~B}_{18}$ is fcc ${ }^{10} \mathrm{Fe}-\mathrm{Ni}$ phase, due to the high nickel

\section{References}

1. Paglieri SN, Pal NK, Dolan MD, Kimb S, Chien W, Lamb $\mathrm{J}$ et al. Hydrogen permeability, thermal stability and hydrogen embrittlement of $\mathrm{Ni}-\mathrm{Nb}-\mathrm{Zr}$ and $\mathrm{Ni}-\mathrm{Nb}-\mathrm{Ta}-$ $\mathrm{Zr}$ amorphous alloy membranes. Journal of Membrane Science. 2011; 378(1-2):42-50. http://dx.doi.org/10.1016/j. memsci.2011.04.049

2. Jayalakshmi S, Vasantha VS, Fleury E and Gupta M. Characteristics of $\mathrm{Ni}-\mathrm{Nb}$-based metallic amorphous alloys for hydrogen-related energy applications. Applied Energy. 2012; 90(1):94-99. http://dx.doi.org/10.1016/j. apenergy.2011.01.040

3. Hara S, Hatakeyama N, Itoh N, Kimura HM and Inoue A. Hydrogen permeation through amorphous- $\mathrm{Zr}_{36-\mathrm{x}} \mathrm{Hf}_{\mathrm{x}} \mathrm{Ni}_{64}$-alloy membranes. Journal of Membrane Science. 2003; $211(1)$ :149156. http://dx.doi.org/10.1016/S0376-7388(02)00416-7

4. Rodmacq B, Goudeau P, Pannetier J and Chamberod A. Neutron diffraction study of the crystallization of hydrogenated $\mathrm{CuTi}$ amorphous alloys. Materials Science and Engineering. 1988; 97:391-394. http://dx.doi. org/10.1016/0025-5416(88)90080-8

5. Fagundes LGS, Torres LFL and Dos Santos DS. Hydrogen diffusivity and solubility in a Fe-based amorphous metallic alloys. Journal of Alloys and Compounds. 2009; 483(1-2):540543. http://dx.doi.org/10.1016/j.jallcom.2008.08.100 content in this alloy. The diffusion capacity in fcc systems ${ }^{10}$ is much smaller when compared with bcc systems ${ }^{6}$. Finally, the values of $\mathrm{D}_{0}$ and $\mathrm{Q}$ obtained in this study are consistent with the diffusion in metallic systems which occurs via interstitial jump mechanisms or in the case of amorphous structure, the arrangements of short-range order ${ }^{11}$.

\section{Conclusions}

The hydrogen diffusivity in the $\mathrm{Fe}_{40} \mathrm{Ni}_{38} \mathrm{Mo}_{4} \mathrm{~B}$ amorphous and partially crystallized alloy was determined at high temperature. The annihilation of structural defects and the partial ordering induced crystallization lead to an increased diffusivity of hydrogen. There was no evidence of changes in the permeation curves suggesting the formation of hydride in the temperature range and hydrogen pressure studied.

\section{Acknowledgements}

The authors acknowledge the CNPq, CAPES and FINEP for the financial support for this research.

6. Fukai Y. The metal-hydrogen system: Basic Bulk Properties. 2nd ed. New York: Springer; 2004. p. 30-36; 326-335.

7. Chiang W, Yeh $\mathrm{W}$ and $\mathrm{Wu}$ J. Hydrogen permeation in $\mathrm{Fe}_{40} \mathrm{Ni}_{38} \mathrm{Mo}_{4} \mathrm{~B}_{18}$ and $\mathrm{Fe}_{81} \mathrm{~B}_{13.5} \mathrm{Si}_{3.5} \mathrm{C}_{2}$ amorphous alloys. Materials Letters. 2005; 59(19-20). http://dx.doi.org/10.1016/j. matlet.2005.03.0422542-2544

8. Du SW and Ramanujan RV. Crystallization and magnetic properties of $\mathrm{Fe}_{40} \mathrm{Ni}_{38} \mathrm{~B}_{18} \mathrm{Mo}_{4}$ amorphous alloy. Journal of Non-Crystalline Solids. 2005; 351(37-39):3105-3113. http:// dx.doi.org/10.1016/j.jnoncrysol.2005.07.028

9. Kim S, Chandra D, Pal NK, Dolan MD, Chien W, Talekar A et al. Hydrogen permeability and crystallization kinetics in amorphous $\mathrm{Ni}-\mathrm{Nb}-\mathrm{Zr}$ alloys. International Journal of Hydrogen Energy. 2012; 37(4):3904-3913. http://dx.doi.org/10.1016/j. ijhydene.2011.04.220

10. Mizgalski KP, Inal OT, Yost FG and Karnowsky MM. The characterization of crystallization in Metglas $2826 \mathrm{MB}$ Alloy. Journal of Materials Science. 1981; 16:3357-3364. http:// dx.doi.org/10.1007/BF00586297

11. Shariq A, Al-Kassab T and Kirchheim R. Studing nearest neighbor correlations by atom probe tomography (APT) in metallic glasses as exemplified for the $\mathrm{Fe}_{40} \mathrm{Ni}_{40} \mathrm{~B}_{20}$ glassy ribbons. Journal of Alloys and Compounds. 2012; 512(1): 270-277. http://dx.doi.org/10.1016/j.jallcom.2011.09.079 